\title{
Impact of diet and nutrition on cancer hallmarks
}

\begin{abstract}
Diet and nutrition are undeniably two factors that have a major impact on the prevention, progression, and treatment of various cancers. In this review, we will discuss how bioactives from diet and nutritional status affect each of the hallmarks of cancer. We will present recent research and discuss using diet and nutrition as a means to prevent and treat cancer.
\end{abstract}

Keywords: cancer hallmarks, bioactives, nutrition, cell proliferation, diet, breast tumors, anthocyanin, nutrition, endometrium, bioactive, cancer, angiogenesis, phosphorylation, Curcumin

\author{
Volume 7 Issue 4 - 2017
}

\author{
Karen L Chen,' Paul Jung, ${ }^{2}$ Eylem \\ Kulkoyluoglu-Cotul, ${ }^{2}$ Carli Liguori, ${ }^{2}$ Jan \\ Lumibao,' Candice Mazewski, ${ }^{2}$ Katherine \\ Ranard,' Joe L Rowles III,' Yanling Wang, ${ }^{2}$ \\ Louisa Xue,' Zeynep Madak-Erdogan ${ }^{1,2}$ \\ 'Division of Nutritional Sciences, University of Illinois, USA \\ ${ }^{2}$ Department of Food Science and Human Nutrition, University \\ of Illinois, USA
}
Correspondence: Zeynep Madak Erdogan, Department of Food Science and Human Nutrition, College of Agricultural, 905 S, Goodwin Avenue Consumer and Environmental Sciences, Urbana, IL 6I80I IL, USA, Tel 217-300-9063,
Email zmadake2@illionis.edu

Received: October 24, 2016 | Published: February 17, 2017
Abbreviations: Scfas, short-chainfatty acids; SFA, saturated fatty acids; MUFA, monounsaturated fatty acids; TFA, trans fatty acids; BBP, blueberry punch; $\mathrm{Rb}$, retinoblastoma protein; $\mathrm{ER}$, estrogen receptor; HCC, hepatocellular carcinoma; MCL, mantle cell lymphoma; SFN, sulforaphane

\section{Introduction}

Cancer cells utilize a large number of pathways and mechanisms to enhance proliferation and metastasize. In an attempt to categorize and define cancer's phenotype, in the most general sense, the "Hallmarks of Cancer" were established in $2000 .{ }^{1}$ then revised in 2011 and have since become a valuable tool in cancer research. ${ }^{2}$ The hallmarks include sustaining proliferative signaling, evading growth suppressors, increased genomic instability and mutations, enabling replicative immortality, reprogramming of energy metabolism, resisting cell death, evading immune destruction, increased tumorpromoting inflammation, activating invasion and metastasis and inducing angiogenesis. Only $5-10 \%$ of cancers are due to hereditary mutations. $90-95 \%$ of cancers are driven by environmental factors mostly determined by lifestyle. ${ }^{3}$ Diet and nutrition are drivers of nearly $40 \%$ of all cancers. Bioactives from diet or signaling pathways activated by nutritional status of the patients affect one or more of the hallmarks of cancer. In this review article, we will present recent research on the role of diet, nutrition, and bioactives on various cancer hallmarks and discuss using bioactives from diet and nutrition as part of a strategy to prevent and treat cancer.

\section{Sustained proliferative signaling}

Sustained proliferative signaling is the cancer hallmark which is "arguably the most fundamental trait of cancer cells". ${ }^{2}$ Tumor cells display increased sensitivity to growth factors that would increase proliferation of cancer cells and disregard the controls that would otherwise tightly-regulate cell cycle. Diet is a major factor affecting growth factor levels as well as other aspects related to cell proliferation and can influence the onset and development of cancers in a variety of different ways. Levine et al., ${ }^{4}$ links low protein intake with reduced IGF-1 levels and decreased cancer mortality in the aging population particularly. ${ }^{4}$ IGF-1 plays an essential role in proliferative signaling in normal, healthy cells. However, in the context of cancer, IGF-1 not only contributes to tumor growth through pathways which encourage cell proliferation but also inhibit apoptosis and cell cycle arrest pathways.

Insufficient calcium and vitamin D status have also been linked to the suppression of neoplastic colonocytes. ${ }^{5}$ Flavonoids such as apigenin and luteolin, which are present in foods such as parsley, celery, and chamomile tea, have been shown to increase inhibition of pancreatic cell growth in vitro. ${ }^{6}$ Experiments with an extract from the highly nutritive and phenolic-rich foliage of sweet potatoes have demonstrated that it may arrest PC-3 cells in vitro in the G1 phase while also inducing apoptosis by inactivating $\mathrm{Bcl} 2$ and upregulating BAX. Also, the extract from sweet potato greens inhibited tumor cell growth by approximately $69 \%$ in nude mice while normal fast-proliferating cells of the animal, such as epithelial cells, were seemingly unharmed. ${ }^{7}$ There is evidence that molecules called schweinfurthins, found in certain plant leaves, can interfere with PI3K-Akt, a key signaling pathway promoting new cell growth. ${ }^{8}$

Curcumin (from turmeric) and docosahexaenoic acid (derived from omega 3 rich foods) are two bioactives compounds, which have been effective in reducing cell proliferation in certain colorectal cancer cells even in the presence of elevated insulin (a potent proliferative agent). ${ }^{9}$ This was shown to be due inhibition of MEK, upstream of ERK signaling, which induces the upregulated transcription of processes necessary for cell growth. Another food component that may affect colorectal cancer outcome is aged garlic extract. Aged garlic extract was found to inhibit the mitotic cell cycle in human colorectal cancer cells by inactivating NF-B, which led to downregulation of cdk1 and cyclin B1 expression, two key players in cell cycle progression. ${ }^{10}$ Prebiotic foods that enhance the gut microbiota must be considered as well. In one study, BALB/c mice were inoculated with $\mathrm{BaF} 3$ cells and fed inulin-type fructans, which are non-digestible carbohydrates that are fermented by bacteria in the gut, producing short-chain fatty acids (SCFAs). The experimenters showed that the mice that were fed the inulin-type fructans did have an increase in levels of SCFAs that in turn increased propionate in the portal vein and reduced cell 
proliferation via a cAMP-dependent pathway and activation of free fatty acid receptor $2 .{ }^{11}$

Some dietary habits need to be avoided. Many of these are obvious such as consuming refined sugar and high-fat diets. There are also some surprising nutrients which are related to cancer incidence. One of these is folate. Folate in its natural form is highly unlikely to accumulate and cause adverse effects, but due to its potential role in early development, many foods are fortified with the supplement form of folate, folic acid. Folic acid does have the ability to build up to unhealthy levels. Folate can readily act as a growth factor in neoplastic cells. To illustrate this association, researchers assessed the blood levels of folate in men with prostate cancer and found significantly higher folate serum levels in cancer patients than their cancer-free controls. ${ }^{12}$ The impact of dietary fat on both development and progression of human cancers has been studied since the correlation between obesity and cancer was identified. These early studies showed that high level of dietary saturated fat is associated with increased cell proliferation in most of the cancer types. ${ }^{13}$ Due to physiological relation to the steroid hormone production, the majority of research focused on understanding the effect of total fat intake on hormone-dependent cancers such as breast, endometrium, ovary, prostate, testis, thyroid and osteosarcoma. ${ }^{14}$

Several studies were conducted to explain the molecular mechanism of high fat induced cell proliferation in breast tumors, which have demonstrated that the alteration of cell proliferation status depends on the type of dietary fat. Overall, saturated fatty acids (SFA), monounsaturated fatty acids (MUFA) and trans fatty acids (TFA) have been shown to increase breast tumor growth, however, anti-carcinogenic effects of some specific polyunsaturated fatty acids were also reported. ${ }^{15,16}$ In vivo studies showed that long chain saturated fatty acids suppress the mammary tumor growth in comparison to long chain unsaturated fatty acids. ${ }^{17}$ The effect of high total fat intake was also studied in prostate cancer. According to a recent study, high total fat accelerates the initiation and progression of prostatic intraepithelial neoplasia with loss-of-function of the Pten by promoting basal-to-luminal differentiation. ${ }^{18}$

Besides, high fat consumption is also a significant risk factor for hormone-independent cancer types such as gastric cancer. ${ }^{20}$ Recent studies have shown that high fat intake could induce inflammatory markers which potentiate cell proliferation and further mutations in several tumor types. ${ }^{21}$ Tumor cells are highly dependent on fatty acids to replicate their plasma membrane. Thus, fatty acid removal from media prevents production of some essential fatty acids and inhibits cell proliferation. ${ }^{22,23}$ Moreover, increased saturated fat intake enables cancer cells to build hypoxia-resistant plasma membrane. ${ }^{24}$ Several clinical studies showed that being obese or overweight is a significant risk factor for cancer. An in vivo study, which compares the gene and protein expressions of cell proliferation markers in obese and nonobese mouse models, revealed that activation of the AKT/mTOR pathway is higher in obese mice. ${ }^{25}$ b-catenin stabilization is another marker for increased cell proliferation rate and recent studies showed that unsaturated fatty acid accumulation in the cells inhibit the FAF-1 enzyme, which is responsible for b-catenin proteolysis and promote cell proliferation. ${ }^{26}$ These studies highlight the important role of a proper diet affecting the risk of cancer onset and cancer mortality by impacting cell proliferation.

\section{Evading growth suppressors}

Evading growth suppressors is one of cancer hallmarks that have been characterized during the multi-step development of human tumors. There are dozens of tumor suppressors identified to limit cell growth and proliferation, among which $\mathrm{Rb}$ (retinoblastoma protein) and $\mathrm{p} 53$ proteins are two major tumor suppressors. They function by arresting the cell cycle and inhibiting cell proliferation. In normal cells, in response to proliferation signals, E2F, a transcription factor, would activate cell division by activating expression of genes that are important for G1-S transition. When there are no proliferation signals, $\mathrm{E} 2 \mathrm{~F}$ is inactivated by binding to free $\mathrm{Rb}$ protein, so the cells are arrested in G1 phase. However, in cancer cells, $\mathrm{Rb}$ can be inactivated by phosphorylation of Cyclin/Cdk (Cyclin-dependent kinase) complex, resulting in the release of free E2F, which activates the uncontrolled cell division. $\mathrm{p} 53$ is the other principal tumor suppressor. $\mathrm{p} 53$ protein regulates expression of p21 and p27. p21 and p27 act as Cyclin/Cdk inhibitors, which in turn prevents the phosphorylation of $\mathrm{Rb}$ and arresting the cell cycle in G1 phase. In tumor cells, tumor suppressors like $\mathrm{Rb}$ and $\mathrm{p} 53$ are inactivated through mutation, phosphorylation, or epigenetics.

Diet plays a profound role in chemoprevention of cancers. Many papers have shown that the bioactives in the diet including antioxidants from berries, curcumin from turmeric and isothiocyanates from cruciferous vegetables induce the activation of tumor suppressors. In one study, authors found that food extracts from a blueberry fruit juice consumed in the Mediterranean and East Asia suppress prostate cancer proliferation through activation of tumor suppressors. The mixed blueberry punch (BBP) was found to increase the percentage of G0/G1-phase cells, and decrease those at S and G2/M phases in three prostate cancer cell lines (lymph node or bone metastasized; androgen receptor positive or negative). The study suggested that the bioactives in BBP block the G1-S transition and arrest the cell cycle in G0/G1 phase, which is confirmed by decreased DNA synthesis, decreased $\mathrm{Ki}-67$ staining, and decreased $\mathrm{pRb}$ (phosphorylated $\mathrm{Rb}$ ) positive cells. The expression of Cyclin/Cdk complex including Cyclin D1/Cdk4 and Cyclin E/Cdk2 were reduced after treatment with BBP, whereas the expression of $\mathrm{p} 27$, a Cyclin/Cdk inhibitor was elevated. ${ }^{27} \mathrm{~A}$ second paper showed that the pterostilbene, a bioactives stilbenoid from berries and almonds also induced cell cycle arrest. ${ }^{28}$ Pterostilbene treatment with human gastric carcinoma cells significantly increased cell percentage at G0/G1 phase and decreased percentage of cells at $\mathrm{S}$ and $\mathrm{G} 2 / \mathrm{M}$ phases. The protein level of phosphorylated $\mathrm{Rb}$ and Cyclin/Cdk complex were decreased as well, suggesting a successful reactivation of tumor suppressor system. However, there was no effect on Cyclin D1 level. ${ }^{28}$

Given the promising chemoprevention effect of berries, another study ${ }^{29}$ managed to improve anthocyanin level in tomato by introducing anthocyanin synthesis gene from snapdragon flowers. They found the engineered strain with significantly enhanced level of anthocyanin elongated the life span of Trp53-/- knockout mice where the p53 was mutated, further confirmed the anthocyanin possesses the anti-cancer effect in vivo, mainly or partly through restoring the function of tumor suppressors. In contrast to most studies focusing on single bioactive from single food, one study investigated the anti-tumor growth effect of mixed anthocyanidins from mixed berries. ${ }^{30}$ They found that the mixed anthocyanidins synergistically inhibited the growth of two aggressive non-small-cell lung cancer cell lines, by decreasing Cyclin D1 and Cyclin B1 levels, suggesting a synergistic effect of bioactive on activating tumor suppressors. Another bioactive that is well known to inhibit tumor growth is curcumin from turmeric. In one study, the authors found that curcumin reduced expression of Cyclin D1 protein, which resulted in the inhibition of CyclinD1/Cdk4-mediated phosphorylation of $\mathrm{Rb}$ in various prostate, breast, and squamous cell carcinoma cell lines. ${ }^{31}$ However, in contrast to the pterostilbene study, 
not all cyclin protein levels were down-regulated. In this paper, the decrease of Cyclin D2 and Cyclin D3 by curcumin was found only in selective cell lines. Another paper studied the effect of curcumin on human mantle cell lymphoma (MCL), which is characterized by the overexpression of cyclin D1.32 They found curcumin suppressed cell proliferation, cell cycle arrest at the G1/S phase of the cell cycle in all four MCL cell lines through NF-kB pathway.$^{32}$ Moreover, in a recent study, curcumin was found to improve the therapeutic efficacy of cisplatin by targeting cancer stem-like cells through p21 and Cyclin D1-mediated tumor cell inhibition in non-small cell lung cancer cell lines. ${ }^{33}$ Besides the antioxidants and the curcumin, isothiocyanates like sulforaphane (SFN) from broccoli are also able to inhibit tumor growth through targeting cell cycle machinery. In one study, SFN was found to inhibit the activity of $\mathrm{Cdk} 4$ with an upstream induction of Cdk inhibitor p21 and reduced Cyclin D1 in human androgenindependent prostate cancer cells. ${ }^{34}$ This study further showed that the phosphorylation of $\mathrm{Rb}$ proteins was decreased, and the transition from G1 to S phase was inhibited by the SFN treatment. ${ }^{34}$ Another study also showed SFN-induced mitotic arrest in human prostate cancer cell line by induction of tumor suppressor p21 and p53 and the decrease of cyclin D1, cyclin E, Cdk4, and Cdk6. ${ }^{35}$ Similar effect of SFN to arrest cell cycle through tumor suppressors was also found in human osteosarcoma cell lines. ${ }^{36}$ In summary, bioactives including antioxidants, curcumin and SFN are proven to show profound effect on activation of tumor suppressors, especially on inhibition of Cyclin/ Cdk systems and the induction on Cyclin/Cdk inhibitors like p21, which in turn inhibited the phosphorylation of $\mathrm{Rb}$ and arresting the cell cycle in G1 phase.

\section{Increased genomic instability and enabling replicative immortality}

One of the major hallmarks that are involved in cancer progression is genomic instability coming from accumulated DNA damage, which would result in increased number of mutations in oncogenes or tumor suppressors and increased replicative immortality. As DNA damage accumulates, the repair mechanism, which is known as the DNA Damage Response (DDR) comes into play, which would otherwise activate apoptosis if the damage cannot be repaired. However, even though apoptosis is meant to eliminate dysfunctional or pre-cancerous cells, increased apoptosis can cause initiation of certain types of cancers like hepatocellular carcinoma (HCC). During the progression of HCC this increase in the regeneration of hepatocytes leads to more genetic errors that can predispose one to the development of cancer. Tummala et al., ${ }^{37}$ showed that during HCC development Unconventional prefoldin RBP5 Interactor (URI) inhibited NAD+ synthesis, which leads to the accumulation of DNA damage. This reduction in NAD+ synthesis occurs, because URI represses aryl hydrocarbon receptor $(\mathrm{AhR})$ and estrogen receptor (ER), which are transcriptional activators for the rate-limiting enzymes in NAD+ synthesis; tryptophan 2,3-dioxygenase (TDO2) and arylformamidase (AFMID). They showed that enzymes using NAD + as cofactor are inhibited without access to sufficient levels of NAD $+38,39$ Ultimately, the increase in URI did result in more tumorigenicity and the replenishment of NAD+ levels remarkably reversed this. ${ }^{37}$

It is clear that genomic instability is a major hallmark in cancer progression, but the role of bioactives that can affect this hallmark is yet to be fully understood. Elucidating the roles and mechanisms of different bioactives can prove to be of great importance in the clinic. One such bioactive is SFN from cruciferous vegetables that has garnered much attention as a possible anti-cancer bioactive. One study showed that SFN increases apoptosis in MG-63 cells at physiologically relevant concentrations. SFN demonstrated a cytostatic effect by inducing $\mathrm{G} 2 / \mathrm{M}$ phase arrest, with a decrease in checkpoint kinase 1 (Chk1) and M-phase inducer phosphatase 3 $(\mathrm{CDC} 25 \mathrm{C})$ and an increase in cyclin-dependent kinase 1 (CDK1). Ultimately, this study was able to show an accumulation of DNA breaks in an SFN concentration-dependent manner. ${ }^{40}$ Another study suggested that the increase in DNA breaks provided a specific mechanism. They showed that SFN treatment inhibited DNA damage induced PARylation and increased DNA single strand breaks by twofold in HeLA S3 cells. PARP-1 is directly involved in the DDR by binding to damaged DNA sites and recruiting DNA repair proteins, such as X-ray repair cross-complementing protein 1 and DNA ligase III a, via PARylation. The cellular metabolites of SFN directly inhibit PARP-1, which ultimately prevents the signal to recruit the DNA repair proteins resulting in DNA damage accumulation and genomic instability.$^{41}$ This accumulation of DNA damage can eventually lead to apoptosis. In addition, SFN inhibits the expression and activity of telomerase, which is the enzyme that prevents shortening of telomeres and provide further genomic instability and replicative immortality to cancer cells. ${ }^{42-44}$

Another bioactive is curcumin, which is a polyphenol that is derived from Curcuma longa and is shown to have anti-cancer benefits. ${ }^{45}$ One study showed that curcumin could induce cell death in human colorectal hereditary non-polyposis colorectal cancer (HNPCC), by activating c-Abl tyrosine kinase. ${ }^{46}$ Not only does curcumin induce cell death, but it has a potentially selective effect on cancerous cells. When a cancer cell has a faulty mismatch repair (MMR) system, it is more sensitive to the cytotoxic effects of curcumin. As cancerous cells accumulate DNA mutations, it is possible that the MMR system will be abrogated and thus will be more sensitive to curcumin's effects. ${ }^{47}$ The same group also showed that curcumin induced an increase in growth arrest and DNA damage induced protein $\alpha$ (GADD45 $\alpha$ ), which led to increased apoptosis, in HeLa and HNPCC cells and even more so in those cells that had a defective MMR system. When they inhibited GADD45a induction, the cells had increased cell survival. These findings suggest that mutated pre-cancerous cells that have lost their MMR system will be more sensitive to curcumin leading to an up regulation of GADD45a expression.$^{48}$ One of the proteins that increased sensitivity to curcumin via its inhibition was Chk1, which is one of the proteins that were down regulated after SFN treatment. In addition, curcumin also inhibits the telomerase, decrease replicative immortality and genomic instability of cancer cells. ${ }^{49,50}$ These data would suggest a potential beneficial effect in combining SFN and curcumin; as SFN could lower Chk1, which would then prime the cell to be more sensitive to the effects of curcumin. However, it is important to note that, in other studies, curcumin was shown to activate Chk1 and Chk2. ${ }^{40,47}$ In this case, we do not know how using SFN and curcumin in combination would affect the levels of Chk1 and Chk2. That is why it is important to understand the mechanisms of action of more than just individual bioactives. Since bioactives can potentially affect each other and how the cell responds to other bioactives, combination of bioactives and their impact on cancer cells needs further explanation.

Increased apoptosis can lead to the progression of cancer, ${ }^{37}$ which means that the effects of SFN or curcumin may be more hurtful than helpful. Thus, it is important to understand the mechanisms of how a bioactive affects different types of cancers.

\section{Reprogramming of energy metabolism}

Deregulating cellular energetics is a cancer hallmark driven by the need of tumor cells to build macromolecules and provide energy 
for increased cell proliferation and other related processes. Recently, targeting metabolic pathways as a means of cancer treatment has gained more attention. Cancer cells utilize alternative pathways to create energy and biosynthesize products that may be inefficient, but that allow the cells to adapt to difficult environments, such as hypoxia and low lipid availability. De novo lipogenesis is required for cancer progression and survival of cancer cells, especially in lipid-depleted environments. ${ }^{51}$ Fatty acid synthesis requires cytosolic acetyl-CoA, which in normal cells, originates from the TCA cycle. Acetyl-CoA Synthetase 2 (ACSS2) helps provide cancer cells with acetyl-CoA through acetate when carbon sources are low, which enables tumor cells to continue lipogenesis and survive in stressed environments. ${ }^{51,52}$ If ACSS2 can be inhibited, a major source of acetyl-coA can be depleted, and cancer cell growth could be suppressed. Acetyl-coA Synthetase 1 (ACSS1) is also involved in acetate utilization, but unlike ACSS2, its conversion of acetyl-coA takes place in the mitochondria. ACSS1 expression in hepatocellular carcinoma (HCC) is consistent with metabolic changes that indicate increased growth capabilities in hypoxic conditions, suggesting that ACSS1 could be a potential target to inhibit cancer survival, along with ACSS2..$^{53}$ Allicin, a bioactive from garlic, has been shown to inhibit the incorporation of acetate into fatty acid synthesis by inhibiting acetyl-CoA synthase. ${ }^{54}$ It was also shown to affect cancer survival pathways, for example targeting the p53 gene in hepatocellular cancer. ${ }^{55}$ Thus, bioactives from garlic have anti-carcinogenic properties that modulate cellular energetics.

A well-known aspect of this hallmark is the tendency of tumor cells to shift towards anaerobic glycolysis to produce energy, as opposed to oxidative phosphorylation, which is known as the Warburg effect. ${ }^{56}$ Therefore, targeting glycolysis is being considered as an approach for cancer therapies. Various polyphenols may have potential to impact energy metabolism in cancer cells. Resveratrol and quercetin are two of these bioactives that were shown to affect glycolytic metabolism. ${ }^{57}$ Hypoxia inducible factor 1 (HIF-1) plays a role in the aerobic glycolysis shift. It deactivates pyruvate dehydrogenase through activation of PDK1, hindering pyruvate from entering the TCA cycle, and therefore, promoting energy production through means other than oxidative phosphorylation. ${ }^{7}$ Vitamin E, tocotrienols specifically, have shown potential to suppress HIF-1 by way of inhibiting vascular endothelial growth factor (VEGF), an upstream inducer of HIF- $1 .{ }^{58} \mathrm{By}$ suppressing HIF-1 capabilities, pyruvate can be converted to acetyl$\mathrm{CoA}$ and then enter the TCA cycle for energy production. HIF-1 also induces hexokinase II leading to higher rates of aerobic glycolysis seen in tumor cells. ${ }^{59}$ ATP synthesis is inefficient in cancer cells, so more glucose is required to meet the survival and growth needs of the tumor cells. The metabolism of glucose in normal cells is very efficient, but cancer cells cannot yield the maximum ATP per glucose molecule. ${ }^{60}$ GLUT-1 is associated with a greater influx of glucose utilized for energy production in tumor cells. The flavonoid apigenin, was shown to downregulate GLUT-1 in pancreatic cancer cells through P13K/Akt pathway inhibition, indicating that apigenin has potential to decrease glucose uptake in cancer cells. ${ }^{61}$ GLUT1 inhibition was also observed with cryptocaryon, a tropical plant extract, in colon cancer cells. ${ }^{56}$ The nature of tumor cells to adapt to nutritionally complicated environments provides a strong capability for them to survive. However, these shifts from normal metabolic energetics provide a novel means to target specific metabolic vulnerabilities of cancer cells using synthetic drugs as well as, bioactive compounds.

\section{Resisting cell death}

Apoptosis, or programmed cell death can be induced by a variety of factors including DNA damage sensors, limited survival cues, and overactive signaling proteins. There are two main pathways of apoptosis: extrinsic and intrinsic. The extrinsic apoptotic pathway is activated by extracellular signals such as tumor necrosis factor (TNF). The intrinsic apoptotic pathway is mediated by intracellular signaling, such as by activation of caspases or mitochondrial pathways. As such, apoptosis is highly regulated and controlled, a feature that distinguishes apoptosis from necrosis or traumatic cell death due to acute injury. Programmed cell death occurs when cells cannot remedy cell cycle checkpoint arrest. ${ }^{62}$ In normal cells, cell cycle checkpoints slow the cell cycle and allow progression after DNA repair. However, in cancer cells, these checkpoints are disrupted either by gain of function of oncogenes that stimulate the cell cycle or loss of function of tumor suppressors that normally inhibit the cell cycle. Curcumin activates apoptotic pathways in several cancer types including leukemia, cervical, colon, and breast and hepatocellular carcinomas. ${ }^{63}$ It has been suggested that curcumin induces apoptosis by the suppression of fatty acid synthase.${ }^{64}$ Fatty acid synthase (FASN) is responsible for the production of palmitate and is minimally expressed in normal cells. In neoplastic cells, however, FASN has a much higher expression. ${ }^{65}$ Inhibition of FASN by cerulenin or orlistat increased percentage of cells in G0/G1 phase as well as expression of tumor suppressor genes p21 and p53. ${ }^{66}$ Since tumor cells synthesize the majority of fatty acids de novo, stabilization of this protein has been shown to increase cell survival in prostate cancer cells. Destabilization of FASN, such as through ubiquitination after curcumin treatment may, therefore, induce cancer cell apoptosis. ${ }^{65,67}$

SFN also appears to have apoptotic effects on cancer cells. It has been shown to induce apoptosis and inhibit invasion of glioblastoma cells in a dosage-dependent manner. ${ }^{68} \mathrm{SFN}$ induces apoptosis via caspase-dependent pathways on malignant glioma and to shrink tumor size. Daily injection of SFN in a xenograft immune deficient mouse model showed a decrease in mean tumor weight of up to $75 \%$ compared to controls. ${ }^{69}$ In other types of cancers including non-small cell lung cancer, SFN has been shown to not only induce apoptosis but also to inhibit metastasis and progression as well. ${ }^{70}$ Novel antioxidants and those in combination may also have synergistic effects in encouraging apoptosis. Tropical lichen, Parmotrema reticulatum extract can induce cell cycle arrest in breast carcinoma MCF-7 cells that would eventually leading to caspase dependent apoptosis. ${ }^{71}$ Extracts from Partrema reticulatum contains various phytochemicals including flavonoids, phenols, tannins, and ascorbic acid all which have antioxidant activity and cytotoxicity towards MCF-7 cells. More recently, Dillenia suffruticosa, a medicinal plant in Malaysia, root extract was shown to have therapeutic potential against triple negative breast cancer cells. ${ }^{72}$ This extract induced cell cycle arrest as well as oxidative stress. Apoptosis and cell cycle arrest is possibly due to the mitochondrial apoptotic pathway and through a p21 dependent but p53 independent pathway respectively. ${ }^{72}$ Overall it would appear that many phytochemicals target apoptosis through intrinsic pathways rather than extrinsic pathways.

\section{Evading immune destruction}

The immune system is the first line of defense against pathogens. These pathogens can be intracellular (e.g. viruses and parasites) or extracellular (most bacteria and fungi). Additionally, immune surveillance protects against malignant transformation and progression in cancer via destruction of cells harboring oncogenic viruses and recognition of tumor-associated antigens. ${ }^{73,74}$ In this fashion, leukocytes can resist or diminish the formation and progression of tumors. ${ }^{74}$ Both the innate and adaptive branches of the immune system are capable of surveilling and defending against carcinogenesis, as 
evidenced by studies in which immunodeficient mice have been shown to be more susceptible to carcinogen-induced tumorigenesis. ${ }^{74}$ Deficiencies in the function of CD8+ cytotoxic $\mathrm{T}$ lymphocytes (CTLs), CD4+ Th1 helper T cells, and natural killer (NK) cells have been demonstrated to induce increased susceptibility to tumor formation. ${ }^{74}$ Thus, antitumor immunity plays a significant role in malignant cellular transformation and cancer progression. While the cancer immunosurveillance hypothesis has been in existence for over a century, malignant cancers have recently been recognized as capable of suppressing and evading this inherent immune response. . $^{73,75-78}$ Cancer cells employ a variety of molecular mechanisms for the evasion of immune surveillance, including inhibition of tumor antigen presentation by dendritic cells, secretion of immunosuppressant molecules such as TGF- $\beta$, release of death receptor ligands such as Fas to induce $\mathrm{T}$ cell apoptosis, and recruitment of immunosuppressing cells including regulatory T cells. ${ }^{76}$ Among these hijacked molecular pathways, one of the most heavily investigated for targeting in cancer treatment is the immune inhibitory checkpoint. This pathway makes the use of co-receptors expressed on T cells which, when bound by their respective ligands, inhibit $\mathrm{T}$ cell activation. Such a pathway is necessary for immune self-tolerance and modulates the intensity and duration of an immune response. ${ }^{76,79}$ Defects in this signaling axis lead to dysregulated immune responses and autoimmunity. Hence, hijacking this pathway allows cancer cells to suppress the antitumor immune response to promote their own survival. Programmed cell death protein 1 and cytotoxic $\mathrm{T}$ lymphocyte-associated protein 4 are two co-inhibitory receptors that have been extensively studied as some of the most promising therapeutic targets for blockade in cancer immunotherapy. ${ }^{80}$ Programmed cell death protein 1 (PD-1) is an immune checkpoint receptor which controls $\mathrm{T}$ cell activation during inflammatory responses. ${ }^{76}$ Upon binding to either of its ligands PD1 ligand 1 (PD-L1) or PD-L2, PD-1 inhibits kinases downstream of the tyrosine phosphatase SHP2 involved in T cell activation. ${ }^{81} \mathrm{PD}-1$ ligands are commonly upregulated on tumor cell surfaces, facilitating efficient antitumor immune evasion. ${ }^{82}$ With this in mind, blockade of the PD1-PD-L1 interaction presents a lucrative therapeutic target to reactivate the antitumor immune reaction. Various studies using mouse models of cancer demonstrate that antibody blockade of PDL1 enhance antitumor immunity. ${ }^{83,84}$ However, clinical responses to PD-L1 blockade depend on an endogenous, preexisting antitumor T cell response before therapy. ${ }^{78,84}$ The presence of this response can be mediated in part by the gut microbiome, and a recent study comparing the tumor-specific $\mathrm{T}$ cell responses in $\mathrm{C} 57 \mathrm{BL} / 6$ mice obtained from two different mouse facilities supported this hypothesis. ${ }^{74,84-86}$ While genetically similar, mice from Jackson Laboratory (JAX) and mice from Taconic Farms (TAC) differ in the composition of their commensal microbiota. Results from this study indicated significant differences in B16. SIY melanoma growth rate, as tumors grew more aggressively in TAC versus JAX mice, and that the growth was immune mediated, with JAX mice hosting higher tumor-specific T cell responses and intratumoral CD8+ T cell accumulation. These effects were ablated upon cohousing of JAX and TAC mice. Furthermore, transfer of JAX fecal material into TAC mice was sufficient to delay tumor growth. Sequencing of $16 \mathrm{~S}$ rRNA revealed Bifidobacterium as the bacterial species associated with these antitumor effects, and treatment of TAC mice with Bifidobacterium alone was sufficient to induce an antitumor immune response and control tumor growth. Combining Bifidobacterium treatment with anti-PD-L1 antibody immunotherapy led to even further improved tumor control. These results provide strong evidence illustrating the auspicious link between the gut microbiome and the antitumor immune response and demonstrate the ability of the gut microbiome to augment cancer immunotherapy.
In addition to $\mathrm{PD}-1$, cytotoxic $\mathrm{T}$ lymphocyte-associated protein 4 (CTLA-4) is a major negative regulator of T cell activation. ${ }^{80,86}$ Although the specific molecular pathway by which CTLA-4 confers immunosuppression is still under debate, its central regulatory role as an immune suppressor has been demonstrated by a dramatic and lethal autoimmune response in Ctla4-knockout mice. ${ }^{87}$ Antibody blockade of CTLA-4 has been used as a successful cancer immunotherapeutic strategy, particularly in metastatic melanoma. Ipilimumab, a monoclonal antibody against CTLA-4, had been FDA approved in 2011 for melanoma. ${ }^{14}$ However, in a similar fashion as the PD-L1 blockade, CTLA-4 blockade alone is not sufficient to launch a significant antitumor immune response, as an endogenous preexisting immune response is necessary for the CTLA-4 blockade to further enhance. ${ }^{12}$ A recent study by Vétizou et al. ${ }^{86}$ provides further evidence that the antitumor efficacy of CTLA-4 blockade is intimately linked to the gut microbiome. ${ }^{86}$ It compared the efficacy of anti-CTLA-4 antibody treatment against established MCA205 sarcomas in mice housed in either specific pathogen-free (SPF) or germ-free (GF) conditions. Tumor growth was controlled by CTLA-4 blockade in SPF but not GF mice, suggesting that the gut microbiota is necessary for CTLA-4 blockade-induced antitumor immune response. High-throughput pyrosequencing of $16 \mathrm{~S}$ rRNA gene amplicons of feces, as well as analysis of the gut microbiome before and after treatment of 25 metastatic melanoma patients with ipilimumab, revealed Bacteroides thetaiotaomicron and Bacteroides fragilis as immunogenic bacteria necessary in the therapeutic response of anti-CTLA-4 antibody treatment. Specifically, patient stools after ipilimumab therapy displayed increased numbers of bacterial clusters driven by Bacteroides spp. Further, transplant of feces from patients in this Bacteroides spp. driven cluster into mice led to marked responses in tumor growth control as a result of CTLA-4 treatment. These results provide further evidence supporting the hypothesis that the gut microbiota influences the efficacy of anti-immunosuppressive cancer immunotherapies.

In addition to the mediating effects of the gut microbiota on the antitumor immune response, certain nutrients and food bioactives have recently been demonstrated to affect tumor immunosurveillance positively. In a nested case-control study within the Nurses' Health Study and Health Professionals Follow-up Study, Song et al. showed that high plasma 25-hydroxyvitamin D $25(\mathrm{OH}) \mathrm{D}$ is associated with lower risk of the colorectal cancer subtype characterized by highdegree lymphocytic reaction. ${ }^{88}$ It is possible that conversion of $25(\mathrm{OH}) \mathrm{D}$ to active $1,25(\mathrm{OH}) \mathrm{D}$ by immune cells renders Vitamin D capable of binding to VDR in cancer cells and regulating expression of genes involved in cell proliferation and apoptosis. ${ }^{88}$ In addition to Vitamin D, food bioactives such as phytochemicals present in black raspberries have been investigated for their anticancer potential in the context of immunomodulation. In an in vitro study, Mace et al., ${ }^{89}$ demonstrated that ethanol extracts of black raspberries decreased the amount of CD4+ and CD8 $+\mathrm{T}$ cells expressing the CTLA-4 and PD-1 receptors, thus reducing the load of T cells susceptible to immunosuppression. ${ }^{89}$ Other in vivo studies in mice have documented the ability of grape seed proanthocyanidins to reduce UV-induced immunosuppression, another mechanism which allows for the onset and progression of skin carcinogenesis. ${ }^{90,91}$ Thus, in addition to the composition of the gut microbiome, nutritive status and certain bioactive components of foods also contribute to priming the immune system for a swift antitumor immune response. In summary, the immune system provides a defense against not only conventional extra- and intracellular pathogens but also malignant transformation and progression of cancers. Malignant cancers possess the capacity to evade this immune response by many pathways, the most notable 
of which is arguably immunosuppression via the PD-1/PD-L1 and CTLA-4 signaling pathways. Antibody blockade of these inhibitory axes has proven to be an effective strategy in cancer immunotherapy, and the gut microbiome plays an essential role in augmenting the response seen by priming the inherent antitumor immune response. Nutrients and food bioactives also play roles in diminishing the immunosuppressive capacity of cancer cells. Future studies should further elucidate these mechanistic pathways, investigate the effects of microbiome alterations and subsequent effects on antitumor immunity as a result of probiotic consumption, and further characterize the role of identified bacteria of the microbiome in enhancing the immune response against cancer.

\section{Increased tumor-promoting inflammation}

Cancer is an ever changing disease, and the need for additional "Hallmarks" soon became apparent. In 2011, a few additions were made to the original list. Among the "Emerging Hallmarks" is the reprogramming of energy metabolism. ${ }^{2}$ It is well established that cancer cells utilize the glycolytic pathway, even in the presence of adequate oxygen, resulting in an increase in the production of lactate and increased anaerobic glycolysis. ${ }^{92}$ While cancer cells can easily provide sufficient energy for themselves, it is often at the expense of the energy status of the host. Cancer cachexia, although common, largely remains a mystery. One proposed theory involves inflammatory cytokines. By targeting Fn14, a TWEAK receptor, with antibodies in mice, tumor-induced cachexia was reduced, and lifespan was prolonged..$^{93}$ Additional research has shown the importance of the TWEAK-Fn14 interaction on denervation of muscle resulting in increased atrophy. ${ }^{94}$ The link between cachexia and cytokines sheds light on possible avenues of inhibition. Evidence suggests that levels of pro-inflammatory cytokines, such as TNF $\alpha$, and the ratio of oxidants to antioxidants, such as vitamin E, in the blood can be used as biomarkers to identify cancer patients who are developing cachexia. ${ }^{95}$ However, simply increasing blood concentrations of antioxidants might not mitigate cachexia. Additional studies have found that supplementation of antioxidants, including catechins, quercetin, and vitamin $\mathrm{C}$, can accelerate the rate of cachexia progression in the host by promoting tumor growth. ${ }^{96}$ The findings further exemplify the complexity of cachexia and cancer as a whole. Other bioactives have also been explored in the treatment of cachexia. Ghrelin, an appetitestimulating hormone, has been successfully utilized to increase the impaired appetite of cancer patients..$^{97}$ Ghrelin is well tolerated by even late stage cancer patients, and can be administered at high doses. ${ }^{98}$ It is important to note, however, that ghrelin supplementation does not treat the mechanisms of cachexia. Rather, it should be seen as a way to ease symptoms. In addition to ghrelin, combination therapies including carnitine and celecoxib have been shown to aid in body weight maintenance, improve grip strength, and decrease fatigue in cancer patients with cachexia. ${ }^{99}$

Cancer cells are also capable of deregulating the exportation of glycolytic intermediates pyruvate and lactate via monocarboxylate transporters (MCTs). Blocking MCT1 results in a decrease in private exportation and a reduction in tumor cells proliferation. ${ }^{100}$ Additional research suggests that flavonoids play a role in the regulation of MCT1 in the kidney and may be a potential avenue to explore in tumors. ${ }^{101}$ Most recently, a new pathway resulting in the accumulation of F-fluorodeoxyglucose in the endoplasmic reticulum of tumor cells has revealed a novel mechanism of glucose metabolism utilizing hexose6-phosphate dehydrogenase. ${ }^{102}$ More research is needed to determine the implications of this unique pathway.

\section{Activating invasion \& metastasis}

One cancer hallmark, "activating invasion and metastasis," remains the most deadly for cancer patients; factors like cancer microenvironment and cancer cell heterogeneity block treatment efforts. ${ }^{103}$ Metastasis results from an elegant, yet inefficient, series of steps: epithelial tumor cells invade normal host tissues and create vascular networks; ${ }^{104}$ they lose epithelial cell properties (e.g. adherence via loss of E-cadherin) and transition into mesenchymal cells; ${ }^{2}$ they enter circulation and exit at new sites; and, they reestablish vascularization and defense mechanisms. ${ }^{104}$ Other molecules, such as RHO family proteins and matrix metalloproteinases (MMPs), also play crucial roles, as they impact cell polarity, motility, and the extracellular matrix. ${ }^{105,106}$ Research suggests that SFN has anti-cancer and anti-metastatic capabilities. ${ }^{107,108}$ It's been shown that SFN inhibits invasion and metastasis in multiple cancer cell lines and mouse models. ${ }^{108,109}$ SFN also suppresses MMP-2 transcription and inhibits activation of MMPs in cancer cells. ${ }^{109,110}$ Epidemiological studies also support the benefits of SFN, as cruciferous vegetable intake has been associated with decreased risk of various cancers ${ }^{111,112}$ Curcumin is touted for its anti-cancer properties and has been shown to inhibit lung metastasis in mice. ${ }^{113}$, inhibit cellular migration and invasion in a human hepatocellular carcinoma cell lines and to decrease MMP-9 secretion dose-dependently. ${ }^{114}$ Curcumin also inhibited invasion and metastasis by increasing E-cadherin expression in lung cancer cells. ${ }^{115}$

Antioxidants, which are often exclusively considered white knights (due to their ability to quench free radicals that cause gene mutations) may be Dr. Jekyll/Mr. Hyde-type characters; human clinical trials have failed to prove antioxidants' heroism, and some studies have shown harmful effects, ${ }^{116}$ Dietary antioxidants may be unable to scavenge reactive oxygen species (ROS) at their site of production in cells, and because cancer cells have evolved adaptive mechanisms for tolerating high ROS, they may be unperturbed by supplemented antioxidants. In addition, mitochondrial mutations resulting in increased ROS production further increases metastatic potential by increasing genetic instability. ${ }^{118}$ However, it has also been proposed that antioxidants do reduce ROS in cancer cells, consequently decreasing DNA damage and tumor-suppressor proteins like p53, and increasing cell proliferation/tumor growth; these outcomes were shown by Sayin et al., ${ }^{119}$ in mouse and human lung tumor cells. ${ }^{119}$ Le Gal et al. ${ }^{120}$ also found that antioxidants increased cancer burden and mortality in a mouse melanoma model by activating RHO proteins. ${ }^{120}$ Activation of this protein family increases anchorage independent growth and cytoskeletal remodeling enabling epithelial to mesenchymal transition. A recent study reported that certain antidiabetic drugs including dipeptidyl peptidase- 4 inhibitors increase metastasis by increasing sustained NRF2-mediated antioxidant responses which further validatesrole of antioxidants in increasing metastasis. ${ }^{121}$

Perhaps unsurprisingly, there are conflicting research results for all three dietary components discussed here. Additionally, even with defined mechanisms of action, it is unclear whether consuming the dietary components can translate to dietary patterns. That said, SFN and curcumin can be incorporated into daily diets, e.g. by eating broccoli and turmeric powder, and this supports the overarching idea that eating a balanced diet with healthy foods confers health benefits.

\section{Inducing angiogenesis}

Angiogenesis refers to the growth of capillary-sized blood vessels. ${ }^{122,123}\{$ Niranjana, $2015 \# 199\}$ Like normal tissues, tumors require nutrients and the ability to remove the waste products. ${ }^{2}$ Neovascularization of tumors by angiogenesis fulfills these needs and 
allows the tumor to continue growing. Most tumors stay clinically indolent for decades after initiating events. ${ }^{124,125}$ However, inflammation and upregulation of proangiogenic factors drive angiogenesis and lead to the formation of clinically detectable tumors. Naumov demonstrated that tumors expressing these proangiogenic factors developed palpable tumors significantly faster and more frequently than tumors without these angiogenic factors. ${ }^{126}$ Angiogenesis and inflammation are two host-dependent and interdependent hallmarks of cancer that have early roles in tumorigenesis. ${ }^{2,125}$ This process may be managed by a range of angiogenic factors and inhibitors. ${ }^{122}$ By modulating these factors, tumors may remain indolent and lead to better patient outcomes.

Preventing angiogenesis at early stages is an attractive method to prevent tumor growth that may be accomplished by consumption of bioactive compounds found in many fruits and vegetables. Extensive research has demonstrated that diets high in fruits, vegetables, spices, and grains have potential to reduce cancer risk. ${ }^{123,125,127-132}$ A large array of phytochemicals and bioactives are present in these foods. Many of these compounds also have an impact on angiogenic factors. Here, we will describe a few compounds that demonstrate angio-preventative effects. Carotenoids represent an abundant and diverse group of natural pigments and are present in many fruits and vegetables. ${ }^{131}$ Lycopene and $\beta$-carotene are associated with decreased risk for several cancers including prostate, breast esophageal, lung, stomach, pancreas, and bladder cancer. ${ }^{131}$ This reduced risk may be partially due to various anti-angiogenic effects of these carotenoids. Lycopene significantly upregulates interleukin (IL)-12 and interferon (IFN)- $\gamma .{ }^{123,133}$ IL-12 is a key negative regulator of angiogenesis by stimulating IFN $\gamma$, which mediates production of anti-angiogenic chemokines.$^{134}$ Other studies have found that lycopene may have an anti-angiogenic impact by inhibiting matrix metalloproteinase 2 (MMP-2) and urokinase-type plasminogen activator (UPA) through vascular endothelial growth factor receptor (VEGFR)-2 mediated PI3K-Akt and ERK/p38 signaling pathways, leading to decreased tube formation. ${ }^{123,132,135,136}$ Reduced expression of ras-related $\mathrm{C} 3$ botulinum toxin substrate1 (Rac-1) and increased expression of tissue inhibitors of metalloproteinase-2 (TIMP-2) and plasminogen activator inhibitor-1 (PAI-1) lead to reduced cell migration and invasion. ${ }^{135}$ Studies focusing on $\beta$-carotene demonstrated similar effects. $\beta$-carotene inhibits secretion of VEGF, ${ }^{137}$ which may reduce expression of MMP-2 and MMP-9; increase expression of TIMP1 and TIMP2; alter multiple inflammatory markers and decrease tumordirected capillaries. ${ }^{137,138}$

Over the past 30years, many epidemiological studies have suggested that green tea consumption is correlated with reduced risk for colon, prostate, esophageal, and other types of cancer. ${ }^{125,139}$ The most active component of green tea is (-)-epigallocatechin-3-gallate (EGCG). The anti-angiogenic effects of green tea may be attributed to inhibition of VEGF. ${ }^{125,132,140,141}$ VEGF production is inhibited by the inhibition of ERK-1 and ERK-2 kinases. ${ }^{136,141}$ This inhibition also may reduce or reverse epithelial-mesenchymal transition. The collective result is the reduction of VEGF-induced endothelial cell proliferation, migration and tube formation. ${ }^{140} \mathrm{~A}$ phase II clinical trial evaluated the effects of short-term supplementation of green tea catechins. This supplement was primarily composed of EGCG. VEGF, hepatocyte growth factor (HGF) and insulin-like growth factor 1 (IGF-1) were all reduced with green tea catechin supplementation, suggesting that the tea supplement was effective in reducing markers of angiogenesis. ${ }^{142}$ Another double-blind, placebo-controlled study demonstrated that consuming green tea catechins reduced prostate cancer progression by almost $80 \%$ over two years. ${ }^{143}$ Evidence from these studies demonstrates that long-term exposure to anti-angiogenic compounds can reduce the risk for cancer.

There are many other dietary bioactives that display antiangiogenic effects. For example, curcumin and capsaicin (chili pepper) target multiple genes, growth factors, cytokines and enzymes that affect angiogenesis; ${ }^{122,132,144,145}$ resveratrol affects VEGF, inflammatory markers, growth factors and has been shown to suppress growth of new blood vessels; ${ }^{125,132,145,146}$ and genistein (soy isoflavone) interacts with VEGF, inflammatory markers, and growth factors. ${ }^{125,132,145}$ Angiogenesis is a process that is regulated by many signaling pathways and is targeted by various bioactives. These bioactives are inexpensive, safe and easy to acquire. Consuming foods rich in these bioactives may reduce the risk for clinically relevant cancer by preventing angiogenesis.

\section{Conclusion}

Although the studies that we presented in this review do not necessarily make an absolute judgment on the beneficial effects of consuming these bioactives, it does give us an understanding of the individual effects of these bioactives and their therapeutic potential. Depending on what cancer we are looking at, different bioactives may or may not be helpful and thus unregulated supplementation of these bioactives cannot be assumed to be a good general anti-cancer benefit. Diet and nutrition greatly influence an individual's cancer risk and cancer's progression; this highlights the importance of targeting hallmarks through dietary means. ${ }^{147}$ Although people consume whole foods, not merely food components, a reductionist approach is critical in early research stages and is the focus here. ${ }^{148}$ However, the necessity of a holistic approach, with human trials and real foods, should not be forgotten. The link between cancer, diet, and nutrition may continue to be somewhat elusive, but at the very least, we can work to understand cancer's ten deadly sins.

\section{Acknowledgments}

None.

\section{Conflicts of interest}

Authors declare there are no conflicts of interest.

\section{References}

1. Hanahan D, Weinberg RA. The Hallmarks of Cancer. Cell. 2000;100(1):57-70

2. Hanahan D, Weinberg RA. Hallmarks of Cancer: The Next Generation. Cell. 2011;144(5):646-674.

3. Preetha Anand, Ajaikumar B, Kunnumakara, et al. Cancer is a Preventable Disease that Requires Major Lifestyle Changes. Pharm Res. 2008;25(9):2097-2116.

4. Levine ME, Jorge A Suarez, Sebastian Brandhorst, et al. Low protein intake is associated with a major reduction in IGF-1, cancer, and overall mortality in the 65 and younger but not older population. Cell Metab. 2014;19(3):407-417.

5. Aggarwal A, Höbaus J, Tennakoon S, et al. Active vitamin D potentiates the anti-neoplastic effects of calcium in the colon: A cross talk through the calcium-sensing receptor. J Steroid Biochem Mol Biol. 2016;155(Pt B):231-238

6. Johnson JL, Gonzalez de Mejia E. Interactions between dietary flavonoids apigenin or luteolin and chemotherapeutic drugs to potentiate anti-proliferative effect on human pancreatic cancer cells, in vitro. Food Chem Toxicol. 2013;60:83-91. 
7. Karna P, Gundala SR, Gupta MV, et al. Polyphenol-rich sweet potato greens extract inhibits proliferation and induces apoptosis in prostate cancer cells in vitro and in vivo. Carcinogenesis. 2011;32(12):1872-1880.

8. Bao X, Zheng W, Hata Sugi N, et al. Small molecule schweinfurthins selectively inhibit cancer cell proliferation and mTOR/AKT signaling by interfering with trans-Golgi-network trafficking. Cancer Biol Ther. 2015;16(4):589-601.

9. Fenton JI, McCaskey SJ. Curcumin and docosahexaenoic acid block insulin-induced colon carcinoma cell proliferation. Prostaglandins Leukot Essent Fatty Acids. 2013;88(3):219-226.

10. Jikihara H, Qi G, Nozoe K, et al. Aged garlic extract inhibits 1,2-dimethylhydrazine-induced colon tumor development by suppressing cell proliferation. Oncol Rep. 2015;33(3):1131-1140.

11. Bindels LB, Porporato P, Dewulf EM, et al. Gut microbiota-derived propionate reduces cancer cell proliferation in the liver. $\mathrm{Br} J$ Cancer. 2012;107(8):1337-1344.

12. Tomaszewski JJ, Cummings JL, Parwani AV, et al. Increased cancer cell proliferation in prostate cancer patients with high levels of serum folate. Prostate. 2011;71(12):1287-1293.

13. La Vecchia C. Cancers associated with high-fat diets. J Natl Cancer Inst Monogr. 1992;12:79-85.

14. Henderson BE, Feigelson HS. Hormonal carcinogenesis. Carcinogenesis 2000;21(3):427-433.

15. MacLennan M, Ma DW. Role of dietary fatty acids in mammary gland development and breast cancer. Breast Cancer Res. 2010;12(5):211.

16. Park JM, Kwon SH, Han YM, et al. Omega-3 polyunsaturated Fatty acids as potential chemopreventive agent for gastrointestinal cancer. $J$ Cancer Prev. 2013;18(3):201-208.

17. Currie E, Schulze A, Zechner R, et al. Cellular Fatty Acid Metabolism and Cancer. Cell Metab. 2013;18(2):153-161.

18. Kwon OJ, Zhang B, Zhang L, et al. High fat diet promotes prostatic basal-to-luminal differentiation and accelerates initiation of prostate epithelial hyperplasia originated from basal cells. Stem Cell Res. 2016;16(3):682-691.

19. Han J, Jiang Y, Liu X, et al. Dietary Fat Intake and Risk of Gastric Cancer: A Meta-Analysis of Observational Studies. PLoS One. 2015;10(9):e0138580.

20. Kiraly O, Gong G, Olipitz W, et al. Inflammation-induced cell proliferation potentiates DNA damage-induced mutations in vivo. PLoS Genet. 2015;11(2):e1004901.

21. Kamphorst JJ, Cross JR, Fan J, et al. Hypoxic and Ras-transformed cells support growth by scavenging unsaturated fatty acids from lysophospholipids. Proc Natl Acad Sci U S A. 2013;110(22):8882-8887.

22. Young RM, Ackerman D, Quinn ZL, et al. Dysregulated mTORC1 renders cells critically dependent on desaturated lipids for survival under tumor-like stress. Genes Dev. 2013;27(10):1115-1131.

23. Rysman E, Brusselmans K, Scheys K, et al. De novo lipogenesis protects cancer cells from free radicals and chemotherapeutics by promoting membrane lipid saturation. Cancer Res. 2010;70(20):8117-8126.

24. Fuentes-Mattei E, Velazquez-Torres G, Phan L, et al. Effects of obesity on transcriptomic changes and cancer hallmarks in estrogen receptorpositive breast cancer. J Natl Cancer Inst.2014;106 (7).

25. Kim H, Rodriguez-Navas C, Kollipara RK, et al. Unsaturated Fatty Acids Stimulate Tumor Growth through Stabilization of beta-Catenin Cell Rep. 2015;13(3):496-503.

26. Yao M, Xie C, Constantine M, et al. How can food extracts consumed in the Mediterranean and East Asia suppress prostate cancer proliferation?. Br J Nutr. 2012;108(3):424-430.
27. Pan MH, Chang YH, Badmaev V, et al. Pterostilbene induces apoptosis and cell cycle arrest in human gastric carcinoma cells. J Agric Food Chem. 2007;55(19):7777-7785.

28. Butelli E, Titta L, Giorgio M, et al. Enrichment of tomato fruit with health-promoting anthocyanins by expression of select transcription factors. Nat Biotechnol. 2008;26(11):1301-1308.

29. Kausar H, Jeyabalan J, Aqil F, et al. Berry anthocyanidins synergistically suppress growth and invasive potential of human non-small-cell lung cancer cells. Cancer Lett. 2012;325(1):54-62.

30. Mukhopadhyay A, Banerjee S, Stafford LJ, et al. Curcumin-induced suppression of cell proliferation correlates with down-regulation of cyclin D1 expression and CDK4-mediated retinoblastoma protein phosphorylation. Oncogene. 2002;21(57):8852-8861.

31. Shishodia S, Amin HM, Lai R, et al. Curcumin (diferuloylmethane) inhibits constitutive NF-kappaB activation, induces G1/S arrest, suppresses proliferation, and induces apoptosis in mantle cell lymphoma. Biochem Pharmacol. 2005;70(5):700-713.

32. Baharuddin P, Satar N, Fakiruddin KS, et al. Curcumin improves the efficacy of cisplatin by targeting cancer stem-like cells through p21 and cyclin D1-mediated tumour cell inhibition in non-small cell lung cancer cell lines. Oncol Rep. 2016;35(1):13-25.

33. Wang L, Liu D, Ahmed T, et al. Targeting cell cycle machinery as a molecular mechanism of sulforaphane in prostate cancer prevention. Int J Oncol . 2004;24(1):187-192.

34. Herman-Antosiewicz A, Xiao H, Lew KL, et al. Induction of p21 protein protects against sulforaphane-induced mitotic arrest in LNCaP human prostate cancer cell line. Mol Cancer Ther. 2007;6(5):1673-1681.

35. Kim MR, Zhou L, Park BH, et al. Induction of $\mathrm{G}(2) / \mathrm{M}$ arrest and apoptosis by sulforaphane in human osteosarcoma U2-OS cells. Mol Med Rep. 2011;4(5):929-934.

36. Malhi H, Gores GJ. Cellular and molecular mechanisms of liver injury. Gastroenterology. 2008;134(6):1641-1654

37. Tummala KS, Gomes AL, Yilmaz M, et al. Inhibition of de novo $\mathrm{NAD}(+)$ synthesis by oncogenic URI causes liver tumorigenesis through DNA damage. Cancer Cell. 2014;26(6):826-839.

38. Herceg Z, Wang ZQ. Functions of poly(ADP-ribose) polymerase (PARP) in DNA repair, genomic integrity and cell death. Mutat Res. 2001;477(1-2):97-110.

39. Ferreira de Oliveira JM, Remédios C, Oliveira H, et al. Sulforaphane induces DNA damage and mitotic abnormalities in human osteosarcoma MG-63 cells: correlation with cell cycle arrest and apoptosis. Nutr Cancer. 2014;66(2):325-334.

40. Piberger AL, Keil C, Platz S, et al. Sulforaphane inhibits damageinduced poly (ADP-ribosyl)ation via direct interaction of its cellular metabolites with PARP-1. Mol Nutr Food Res. 2015;59(11):2231-2242.

41. Abbas A, Hall JA, Patterson WL, et al. Sulforaphane modulates telomerase activity via epigenetic regulation in prostate cancer cell lines. Biochem Cell Biol. 2016;94(1):71-81.

42. Chen H, Landen CN, Li Y, et al. Epigallocatechin gallate and sulforaphane combination treatment induce apoptosis in paclitaxel-resistant ovarian cancer cells through hTERT and Bcl-2 down-regulation. Exp Cell Res. 2013;319(5):697-706.

43. Meeran SM, Patel SN, Tollefsbol TO. Sulforaphane Causes Epigenetic Repression of hTERT Expression in Human Breast Cancer Cell Lines. PLOS ONE. 2010;5(7):e11457.

44. Sharma RA, Gescher AJ, Steward WP. Curcumin: the story so far. Eur J Cancer. 2005;41(13):1955-1968. 
45. Kamath R, Jiang Z, Sun G, et al. c-Abl kinase regulates curcumininduced cell death through activation of c-Jun N-terminal kinase. Mol Pharmacol. 2007;71(1):61-72.

46. Jiang Z, Jin S, Yalowich JC, et al. The mismatch repair system modulates curcumin sensitivity through induction of DNA strand breaks and activation of G2-M checkpoint. Mol Cancer Ther. 2010;9(3):558-568.

47. Mosieniak G, Sliwinska MA, Przybylska D, et al. Curcumin-treated cancer cells show mitotic disturbances leading to growth arrest and induction of senescence phenotype. Int $J$ Biochem Cell Biol. 2016;74:33-43

48. Rana C, Piplani H, Vaish V, et al. Downregulation of telomerase activity by diclofenac and curcumin is associated with cell cycle arrest and induction of apoptosis in colon cancer. Tumour Biol. 2015;36(8):5999-6010.

49. Kazemi-Lomedasht F, Rami A, Zarghami N. Comparison of Inhibitory Effect of Curcumin Nanoparticles and Free Curcumin in Human Telomerase Reverse Transcriptase Gene Expression in Breast Cancer. Adv Pharm Bull. 2013;3(1):127-30.

50. Schug ZT, Peck B, Jones DT, et al. Acetyl-CoA Synthetase 2 Promotes Acetate Utilization and Maintains Cancer Cell Growth under Metabolic Stress. Cancer Cell. 2015;27(1):57-71.

51. Alderton GK. Metabolism: Acetate noursihes stressed tumour cells. Nat Rev Cancer. 2015;15(2):67.

52. Björnson E, Mukhopadhyay B, Asplund A, et al. Stratification of Hepatocellular Carcinoma Patients Based on Acetate Utilization. Cell Rep. 2015;13(9):2014-2026.

53. Focke M, Feld A, Lichtenthaler K. a naturally occuring antibiotic from garlic, specifically inhibits acetyl-CoA synthetase. FEBS Lett. 1990;261(1):106-108.

54. Chu YL, Ho CT, Chung JG, et al. Allicin induces p53-mediated autophagy in Hep G2 human liver cancer cells. J Agric Food Chem. 2012;60(34):8363-8371.

55. Granchi C, Fancelli D, Minutolo F. An update on therapeutic opportunities offered by cancer glycolytic metabolism. Bioorg Med Chem Lett. 2014;24(21):4915-4925.

56. Keijer J, Bekkenkamp-Grovenstein M, Venema D, et al. Bioactive food components, cancer cell growth limitation and reversal of glycolytic metabolism. Biochim Biophys Acta. 2011;1807(6):697-706.

57. Kannappan R, Gupta SC, Kim JH, et al. Tocotrienols fight cancer by targeting multiple cell signaling pathways. Genes Nutr. 2012;7(1):43-52.

58. Wenner CE. Targeting Mitochondria as a Therapeutic Target in Cancer. J Cell Physiol. 2011;227(2):450-456.

59. Pavlova NN, Thompson CB. The Emerging Hallmarks of Cancer Metabolism. Cell Metab. 2016;23(1):27-47.

60. Melstrom LG, Salabat MR, Ding XZ, et al. Apigenin inhibits the GLUT1 glucose transporter and the phosphoinositide 3-kinase/Akt pathway in human pancreatic cancer cells. Pancreas. 2008;37(4):426-431.

61. Abraham RT. Cell cycle checkpoint signaling through ATM and ATR kinases. Genes Dev. 2001;15(17):2177-2196.

62. Kuo ML, Huang TS, Lin JK. Curcumin, an antioxidant and anti-tumor promotor, induces apoptosis in human leukemia cells. Biochim Biophys Acta. 1996;1317(2):95-100.

63. Zhao J, Sun XB, Ye F, et al. Suppression of fatty acid synthase, differentiation, and lipid accumulation in adipocytes by curcumin. Mol Cell Biochem. 2011;351(1-2):19-28.

64. Priolo C, Tang D, Brahamandan M, et al. The isopeptidase USP2a protects human prostate cancer from apoptosis. Cancer Res. 2006;66(17):8625-8632.
65. Rossato FA, Zecchin KG, La Guardia PG, et al. Fatty acid synthase inhibitors induce apoptosis in non-tumorgenic melan-A cells associated with inhibition of mitochondrial respiration. PLoS One. 2014;9(6):e101060.

66. Graner E, Tang D, Rossi S, et al. The isopeptidase USP2a regulates the stability of fatty acid synthase in prostate cancer. Cancer Cell. 2004;5(3):253-261.

67. Zhang Z, Li C, Shang L, et al. Sulforaphane induces apoptosis and invasion in U251MG glioblastoma cells. Springerplus. 2016;5:235

68. Huang TY, Chang WC, Wang MY, et al. Effect of sulforaphane on growth inhibition in human brain malignant glioma GBM 8501 cells by means of mitochondrial and MEK/ERK-mediated apoptosis pathway. Cell Biochem Biophys. 2012;63(3):247-59.

69. Chen CY, Yu ZY, Chuang YS, et al.Sulforaphane attenuates EGFR signaling in NSCLC cells. J Biomed Sci. 2015;22:38.

70. Ghate NB, Chaudhuri D, Sarkar R, et al. antioxidant extract of tropical lichen, Parmotrema reticulatum, indues cell cycle arrest and apoptosis in breast carcinoma cell line MCF-7. PLoS ONE. 2013;8(12):e82293.

71. Foo JB, Saiful Yazan L, Tor YS, et al. Dillenia suffrcticosa dichloromethane root extract induced apoptosis towards MDAMB-231 triple-negative breast cancer cells. $J$ Ethnopharmacol. 2016;187:195-204.

72. Hanahan D, Weinberg RA. Hallmarks of cancer: the next generation. Cell. 2011;144(5):646-674.

73. Zitvogel L, Ayyoub M, Routy B, et al.Microbiome and Anticancer Immunosurveillance. Cell. 2016;165(2):276-287.

74. Muenst S, Läubli H, Soysal SD, et al. The immune system and cancer evasion strategies: Therapeutic concepts. $J$ Intern Med. 2016;279(6):541-562.

75. O'Byrne K. Stimulating immune responses to fight cancer: Basic biology and mechanisms. Asia Pac J Clin Oncol. 2015;9-15.

76. Rajani KR, Vile RG. Harnessing the power of onco-immunotherapy with checkpoint inhibitors. Viruses. 2015;7(11):5889-58901.

77. Romano E, Romero P. The therapeutic promise of disrupting the PD-1/ PD-L1 immune checkpoint in cancer: unleashing the CD8 T cell mediated anti-tumor activity results in significant, unprecedented clinical efficacy in various solid tumors. J Immunother Cancer. 2015;3:15.

78. Śledzińska A, Menger L, Bergerhoff $\mathrm{K}$, et al. Negative immune checkpoints on $\mathrm{T}$ lymphocytes and their relevance to cancer immunotherapy. Mol Oncol. 2015;9(10):1936-1965.

79. Pardoll DM. The blockade of immune checkpoints in cancer immunotherapy. Nat Rev Cancer. 2012;12(4):252-264

80. Freeman GJ, Long AJ, Iwai Y, et al. Engagement of the PD-1 immunoinhibitory receptor by a novel B7 family member leads to negative regulation of lymphocyte activation. $J$ Exp Med. 2000;192(7):1027-1034

81. Dong H, Strome SE, Salomao DR, et al. Tumor-associated B7-H1 promotes T-cell apoptosis: a potential mechanism of immune evasion. Nat Med. 2002;8(8):793-800.

82. Iwai Y, Ishida M, Tanaka Y, et al. Involvement of PD-L1 on tumor cells in the escape from host immune system and tumor immunotherapy by PD-L1 blockade. Proc Natl Acad Sci U S A. 2002;99(19):12293-12297.

83. Sivan A, Corrales L, Hubert N, et al. Commensal Bifidobacterium promotes antitumor immunity and facilitates anti-PD-L1 efficacy. Science. 2015;350(6264):1084-1089.

84. Nelson MH, Diven MA, Huff LW, et al. Harnessing the Microbiome to Enhance Cancer Immunotherapy. J Immunol Res. 2015;2015:368736. 
85. Vétizou M, Pitt JM, Daillère R, et al. Anticancer immunotherapy by CTLA-4 blockade relies on the gut microbiota. Science. 2015;350(6264):1079-1084.

86. Waterhouse P, Penninger JM, Timms E, et al. Lymphoproliferative disorders with early lethality in mice deficient in Ctla-4. Science. 1995;270(5238):985-988.

87. Song M, Nishihara R, Wang M, et al. Plasma 25-hydroxyvitamin D and colorectal cancer risk according to tumour immunity status. Gut. 2015; 65(2):296-304.

88. Mace TA, King SA, Ameen Z, et al. Bioactive compounds or metabolites from black raspberries modulate $\mathrm{T}$ lymphocyte proliferation, myeloid cell differentiation and Jak/STAT signaling. Cancer Immunol Immunother. 2014;63(9):889-900.

89. Vaid M, Singh T, Li A, et al. Proanthocyanidins inhibit UV-induced immunosuppression through IL-12-dependent stimulation of CD8 + effector T cells and inactivation of CD4 $+\mathrm{T}$ cells. Cancer Prev Res (Phila). 2011;4(2):238-247.

90. Vaid M, Singh T, Prasad R, et al. Bioactive grape proanthocyanidins enhance immune reactivity in UV-irradiated skin through functional activation of dendritic cells in mice. Cancer Prev Res (Phila). 2013;6(3):242-252.

91. Johnston AJ, Murphy KT, Jenkinson L, et al. Targeting of Fn14 Prevents Cancer-Induced Cachexia and Prolongs Survival. Cell. 2015;162(6):1365-1378.

92. Mittal A, Bhatnagar S, Kumar A, et al. The TWEAK-Fn14 system is a critical regulator of denervation-induced skeletal muscle atrophy in mice. J Cell Biol. 2010;188(6):833-849.

93. Assi M, Derbré F, Lefeuvre-Orfila L, et al.Antioxidant supplementation accelerates cachexia development by promoting tumor growth in C26 tumor-bearing mice. Free Radic Biol Med. 2016;91:204-214.

94. Neary NM, Small CJ, Wren AM, et al. Ghrelin increases energy intake in cancer patients with impaired appetite: acute, randomized, placebocontrolled trial. J Clin Endocrinol Metab. 2004;89(6):2832-2836.

95. Strasser F, Lutz TA, Maeder MT, et al. Safety, tolerability and pharmacokinetics of intravenous ghrelin for cancer-related anorexia/ cachexia: a randomised, placebo-controlled, double-blind, doublecrossover study. Br J Cancer. 2008;98(2):300-308.

96. Madeddu C, Dessì M, Panzone F, et al. Randomized phase III clinical trial of a combined treatment with carnitine + celecoxib $+/$ - megestrol acetate for patients with cancer-related anorexia/cachexia syndrome. Clin Nutr. 2012;31(2):176-182.

97. Hong CS, Graham NA, Gu W, et al. MCT1 Modulates Cancer Cell Pyruvate Export and Growth of Tumors that Co-express MCT1 and MCT4. Cell Rep. 2016;14(7):1590-1601.

98. Wang Q, Morris ME. Flavonoids modulate monocarboxylate transporter1-mediated transport of gamma-hydroxybutyrate in vitro and in vivo. Drug Metab Dispos. 2007;35(2):201-208.

99. Marini C, Ravera S, Buschiazzo A, et al. Discovery of a novel glucose metabolism in cancer: The role of endoplasmic reticulum beyond glycolysis and pentose phosphate shunt. Sci Rep. 2016;6:25092.

100. Fidler IJ. The pathogenesis of cancer metastasis: the 'seed and soil' hypothesis revisited. Nat Rev Cancer. 2003;3(6):453-458.

101. Talmadge JE, Fidler IJ. AACR centennial series: the biology of cancer metastasis: historical perspective. Cancer Res. 2010;70(14):5649-5669.

102. Sahai E, Marshall CJ. RHO-GTPases and cancer. Nat Rev Cancer. 2002;2(2):133-142.

103. Deryugina EI,Quigley JP. Matrix metalloproteinases and tumor metastasis. Cancer Metastasis Rev. 2006;25(1):9-34.
104. Singh SV, Singh K. Cancer chemoprevention with dietary isothiocyanates mature for clinical translational research. Carcinogenesis. 2012;33(10):1833-1842.

105. Singh SV, Warin R, Xiao D, et al. Sulforaphane inhibits prostate carcinogenesis and pulmonary metastasis in TRAMP mice in association with increased cytotoxicity of natural killer cells. Cancer Res. 2009;69(5):2117-2125.

106. Thejass P, Kuttan G. Antimetastatic activity of Sulforaphane. Life Sci. 2006;78(26):3043-3050

107. Bertl E, Bartsch H, Gerhauser C. Inhibition of angiogenesis and endothelial cell functions are novel sulforaphane-mediated mechanisms in chemoprevention. Mol Cancer Ther. 2006;5(3):575-585.

108. Higdon JV, Delage B, Williams DE, et al. Cruciferous vegetables and human cancer risk: epidemiologic evidence and mechanistic basis. Pharmacol Res. 2007;55(3):224-236.

109. Juge N, Mithen RF, Traka M. Molecular basis for chemoprevention by sulforaphane: a comprehensive review. Cell Mol Life Sci. 2007;64(9):1105-1127.

110. Menon LG, Kuttan R, Kuttan G. Anti-metastatic activity of curcumin and catechin. Cancer Lett. 1999;141(1-2):159-165.

111. Lin LI, Ke YF, Ko YC, et al. Curcumin inhibits SK-Hep-1 hepatocellular carcinoma cell invasion in vitro and suppresses matrix metalloproteinase-9 secretion. Oncology. 1998;55(4):349-353.

112. Chen HW, Lee JY, Huang JY, et al. Curcumin inhibits lung cancer cell invasion and metastasis through the tumor suppressor HLJ1. Cancer Res. 2008;68(18):7428-7438.

113. Chandel NS, Tuveson DA. The Promise and Perils of Antioxidants for Cancer Patients. N Engl J Med. 2014;371(2):177-178.

114. Goodman GE, Thornquist MD, Balmes J, et al. The Beta-Carotene and Retinol Efficacy Trial: incidence of lung cancer and cardiovascular disease mortality during 6-year follow-up after stopping beta-carotene and retinol supplements. J Natl Cancer Inst. 2004;96(23):1743-1750.

115. Ishikawa $\mathrm{K}$, Takenaga $\mathrm{K}$, Akimoto $\mathrm{M}$, et al. ROS-Generating Mitochondrial DNA Mutations Can Regulate Tumor Cell Metastasis. Science. 2008;320(5876):661-664.

116. Sayin VI, Ibrahim MX, Larsson E, et al. Antioxidants accelerate lung cancer progression in mice. Sci Transl Med. 2014;6(221):221ra15.

117. Le Gal K, Ibrahim MX, Wiel C, et al. Antioxidants can increase melanoma metastasis in mice. Sci Transl Med. 2015;7(308):308re8.

118. Wang H, Liu X, Long M, et al. NRF2 activation by antioxidant antidiabetic agents accelerates tumor metastasis. Sci Transl Med. 2016;8(334):334ra51.

119. Folkman J. Angiogenesis: an organizing principle for drug discovery? Nat Rev Drug Discov. 2015;6(4):273-286.

120. Niranjana R, R Gayathri, Stephen Nimish M, et al. Carotenoids modulate the hallmarks of cancer cells. Journal of Functional Foods. 2015;18:968-985.

121. Senft D, Ronai ZA. Immunogenic, cellular, and angiogenic drivers of tumor dormancy-a melanoma view. Pigment Cell Melanoma Res. 2016;29(1):27-42.

122. Albini A, Tosetti F, Li VW, et al. Cancer prevention by targeting angiogenesis. Nat Rev Clin Oncol. 2012;9(9):498-509.

123. Naumov GN, Bender E, Zurakowski D, et al. A model of human tumor dormancy: an angiogenic switch from the nonangiogenic phenotype. $J$ Natl Cancer Inst. 2006;98(5):316-325.

124. Giovannucci E. Tomatoes, tomato-based products, lycopene, and cancer: review of the epidemiologic literature. J Natl Cancer Inst. 1999;91(4):317-331. 
125. Anand P, Ajaikumar B Kunnumakara, Chitra Sundaram, et al. Cancer is a preventable disease that requires major lifestyle changes. Pharm Res. 2008;25(9):2097-2116.

126. Kavanaugh CJ, Trumbo PR, Ellwood KC. The U.S. Food and Drug Administration's evidence-based review for qualified health claims: tomatoes, lycopene, and cancer. $J$ Natl Cancer Inst. 2007;99(14):1074-1085.

127. Turati F, Rossi M, Pelucchi C, et al. Fruit and vegetables and cancer risk: a review of southern European studies. Br J Nutr. 2015;113(Suppl 2):S102-S110.

128. Krinsky NI, Johnson EJ. Carotenoid actions and their relation to health and disease. Mol Aspects Med. 2005;26(6):459-516.

129. Gupta SC, Kim JH, Prasad S, et al. Regulation of survival, proliferation, invasion, angiogenesis, and metastasis of tumor cells through modulation of inflammatory pathways by nutraceuticals. Cancer Metastasis Rev. 2010;29(3):405-434.

130. Huang CS, Chuang CH, Lo TF, et al. Anti-angiogenic effects of lycopene through immunomodualtion of cytokine secretion in human peripheral blood mononuclear cells. J Nutr Biochem. 2013;24(2):428-434

131. Noonan DM, De Lerma Barbaro A, Vannini N, et al. Inflammation, inflammatory cells and angiogenesis: decisions and indecisions. Cancer Metastasis Rev. 2008;27(1):31-40.

132. Chen ML, Lin YH, Yang CM, et al. Lycopene inhibits angiogenesis both in vitro and in vivo by inhibiting MMP-2/uPA system through VEGFR2mediated PI3K-Akt and ERK/p38 signaling pathways. Mol Nutr Food Res. 2012;56(6):889-899.

133. Aprile G, Ongaro E, Del Re M, et al. Angiogenic inhibitors in gastric cancers and gastroesophageal junction carcinomas: A critical insight. Crit Rev Oncol Hematol. 2015;95(2):165-178.

134. Chen HY, Huang SM, Yang CM, et al. Diverse effects of beta-carotene on secretion and expression of VEGF in human hepatocarcinoma and prostate tumor cells. Molecules. 2012;17(4):3981-3988.

135. Guruvayoorappan C, Kuttan G. Beta-carotene inhibits tumor-specific angiogenesis by altering the cytokine profile and inhibits the nuclear translocation of transcription factors in B16F-10 melanoma cells. Integr Cancer Ther. 2007;6(3):258-270.
136. Johnson JJ, Bailey HH, Mukhtar H. Green tea polyphenols for prostate cancer chemoprevention: a translational perspective. Phytomedicine. 2010;17(1):3-13.

137. Zhu BH, Zhan WH, Li ZR, et al. (-)-Epigallocatechin-3-gallate inhibits growth of gastric cancer by reducing VEGF production and angiogenesis. World J Gastroenterol. 2007;13(8):1162-1169.

138. Jung YD, Kim MS, Shin BA, et al. EGCG, a major component of green tea, inhibits tumour growth by inhibiting VEGF induction in human colon carcinoma cells. Br J Cancer. 2001;84(6):844-850.

139. McLarty J, Bigelow RL, Smith M, et al. Tea polyphenols decrease serum levels of prostate-specific antigen, hepatocyte growth factor, and vascular endothelial growth factor in prostate cancer patients and inhibit production of hepatocyte growth factor and vascular endothelial growth factor in vitro. Cancer Prev Res (Phila). 2009;2(7):673-682.

140. Brausi M, Rizzi F, Bettuzzi S. Chemoprevention of human prostate cancer by green tea catechins: two years later. A follow-up update. Eur Urol. 2008;54(2):472-473.

141. Yadav VR, Aggarwal BB. Curcumin: a component of the golden spice, targets multiple angiogenic pathways. Cancer Biol Ther. 2011;11(2):236-241.

142. Tosetti F, Noonan DM, Albini A. Metabolic regulation and redox activity as mechanisms for angioprevention by dietary phytochemicals. Int J Cancer. 2009;125(9):1997-2003.

143. Brakenhielm E, Cao R, Cao Y. Suppression of angiogenesis, tumor growth, and wound healing by resveratrol, a natural compound in red wine and grapes. FASEB J. 2001;15(10):1798-1800.

144. World cancer research fund. Food, Nutrition, Physical Activity and the Prevention of Cancer: a Global Perspective. American Institute for Cancer Research; 2007. 537 p.

145. Mayne ST, Playdon MC, Rock CL. Diet, nutrition, and cancer: past, present and future. Nat Rev Clin Oncol. 2016;13(8):504-515. 